Vol 1. No. 4, Oktober 2021 P-ISSN : 2774-8014, e-ISSN : 2774-7034

\title{
MENINGKATKAN PRESTASI BELAJAR SISWA DALAM PEMBELAJARAN DARING DI MASA PANDEMI MELALUI APLIKASI CANVA UNTUK KELAS VI SDN KREMBANGAN SELATAN III SURABAYA
}

\author{
MARYUNANI \\ SDN Krembangan Selatan III Surabaya \\ Email : marainibasori@gmail.com
}

\begin{abstract}
ABSTRAK
Penelitian ini bertujuan untuk memastikan keterlaksanaan pembelajaran daring di SDN Krembangan Selatan III selama pandemi COVID-19, dan mengukur kemampuan guru dalam merancang serta melaksanakan pembelajaran daring yang kreatif dan inovatif sesuai dengan kondisi siswa selama School From Home (SFH). Guru melaksanakan pembelajaran berbasis digital dengan menggunakan aplikasi Canva dalam menyampaikan materi pembelajaran kepada siswa. Aplikasi canva merupakan salah satu aplikasi pilihan yang dirasa sangat tepat untuk menyajikan materi pelajaran secara daring. Canva untuk Pendidikan adalah fitur tambahan untuk pembelajaran daring yang interaktif, pembelajaran menyeluruh, dan proses pembelajaran bisa dilakukan secara virtual. Canva untuk Pendidikan digunakan sebagai media lingkungan belajar yang menyamai kelangsungan, akses, dan struktur pendidikan yang membuat pentingnya pembelajaran daring. Penulis menggunakan metode penelitian pengembangan atau Research \& Development $(R \& D)$. Hasil analisis menunjukkan bahwa kreativitas pembelajaran daring di SDN Krembangan Selatan III Surabaya Tahun 2020 telah mencapai tujuan yang diharapkan yaitu setelah siswa menggunakan aplikasi Canva pembelajaran tidak monoton, dan hasilnya berdampak pada prestasi akademik siswa. Nilai rata-rata mereka naik, yang awalnya hanya sebesar 67,4 menjadi 82 . Penggunaan aplikasi canva juga mempengaruhi besarnya presentase siswa yang lolos KKM, dari 33\% meningkat menjadi $87 \%$ jumlah siswa yang lolos KKM setelah melakukan pembelajaran dengan menggunakan canva
\end{abstract}

Kata kunci: pembelajaran daring, prestasi belajar siswa, aplikasi canva

\section{ABSTRACT}

This study aims to ensure the implementation of online learning at SDN Krembangan Selatan III during the COVID-19 pandemic, and to measure the ability of teachers to design and implementing creative and innovative online learning according to students' conditions during School From Home (SFH). Teachers carry out digital-based learning by using applications in delivering learning materials to students. Canva application is one of the preferred applications that is considered very appropriate for presenting subject matter online. Canva for Education is an add-on fiture for interactive and comprehensive online learning, also the teaching and learning process can be conducted virtually. Canva for Education can help facilitate a learning environment that matches the continuity, access, and structure of education that makes online learning important. In this study, the researcher using the Research and Development (R\&D) methods. The results of the analysis show that online learning creativity at SDN Krembangan Selatan III Surabaya in 2020 has achieved the expected goal, namely after students use the Canva application, learning is not monotonous, and the results have an impact on student academic achievement. Their average score rose, which was initially only 67.4 to 82 . The use of the Canva application also affects the percentage of students who pass the mínimum criteria of mastery learning (KKM) from 33\% increas to $87 \%$ after learning using Canva.

Keyword: Online learning, students achievement, Canva App

\section{PENDAHULUAN}

COVID-19 telah menjadi pandemi sejak awal tahun 2020 sehingga semua kegiatan dilaksanakan di dalam rumah termasuk kegiatan belajar mengajar. Karena diberlakukannya hal tersebut, prestasi belajar siswa berbanding terbalik dengan sebelum pendemi COVID-19 
berlangsung. Para siswa mengeluh tentang bagaimana membosankannya belajar melalui daring seperti ini. Mereka menyebutkan bahwa pembelajaran daring tidak seru, sehingga motivasi belajar mereka menurun drastis dan berdampak pada keantusiasan siswa dalam kegiatan belajar mengajar Hal ini berbanding terbalik dengan suasana belajar sebelum pandemi COVID-19 berlangsung. Saat pembelajaran offline atau tatap muka, keantusiasan siswa dapat terlihat dengan keaktifan mereka saat proses belajar mengajar berlangsung dan berdampak pada hasil prestasi belajar siswa yang melebihi KKM. Setelah diselidiki, ternyata hal ini disebabkan oleh monotonnya kegiatan pembelajaran yang diberikan oleh guru.

Dalam menyampaikan materi pembelajaran daring, guru hanya mrnggunakan satu aplikasi yang sama yang membuat siswa bosan dan kurang berminat. Kebanyakan siswa hanya mengerjakan soal-soal pilihan ganda. Guru tidak menyertakan materi yang luas apalagi media belajar yang cukup. Media yang digunakan kurang bervariasi, mengingat aplikasi yang digunakan kurang memadai, sehingga berdampak pada prestasi belajar siswa. Dibuktikan dengan hasil Penilaian Harian siswa yang pada awal sebelum diterapkan aplikasi canva ratarata 67.4, dan hanya 10 siswa dari 30 siswa yang tuntas.

Di masa seperti ini, guru dan siswa diharuskan dapat memanfaatkan teknologi untuk menunjang proses belajar mengajar. Penggunaan teknologi dalam kegiatan belajar mengajar saat ini menjadi salah satu hal yang signifikan. Pemanfaatan media pembelajaran merupakan salah satu elemen yang berperan penting dalam keberhasilan proses pembelajaran terlebih saat pandemic seperti ini sedang berlangsung. Media pembelajaran adalah sesuatu yang digunakan untuk menyampaikan materi atau informasi dalam proses belajar mengajar. Media pembelajaran merupakan alat yang digunakan sebagai penyalur informasi kepada penerimanya sehingga peerima dapat melakukan proses belajar mengajar secara efektif dan efisien yang akan menciptakan lingkungan belajar yang kondusif dan dapat lebih menarik minat siswa untuk belajar (Munadi, 2008:7). Media pembelajaran berperan penting dalam proses penyampaian materi agar materi yang di sampaikan lebih mudah diterima oleh siswa terlebih saat kegiatan belajar mengajar dilakukan secara daring seperti saat ini. Oleh sebab itu dibutuhkan berbagai aplikasi pembelajaran untuk menyampaikan materi ajar dalam pembelajaran jarak jauh, salah satunya adalah aplikasi Canva

Canva untuk Pendidikan merupakan salah satu fitur yang ada di dalamnya. Canva untuk Pendidikan bersifat interaktif, menyeluruh, dan mudah digunakan secara virtual. Kelebihan yang dimiliki aplikasi ini adalah mudahnya aplikasi ini di akses melalui ponsel. Menurut Faiza (2019), aplikasi Canva memiliki desain yang menarik, sehingga mampu meningkatkan kreativitias guru dan siswa dalam mendesain media pembelajaran karena fitur-fitur di dalam aplikasi ini pun sangat mudah digunakan, menghemat waktu dalam mendesain media pembelajaran.

Berdasarkan uraian tersebut, penerapan aplikasi Canva sebagai media pembelajaran diharapkan dapat memberikan manfaat kepada berbagai pihak. (1) Bagi siswa, diharapkan mampu memahami materi pembelajaran yang diberikan guru selama pembelajaran daring, 2) Bagi guru, aplikasi canva mampu dijadikan sebagai salah satu inovasi pembelajaran untuk dikembangkan agar lebih menarik, 3) Bagi sekolah, aplikasi canva mampu dijadikan pilihan dalam menyampaikan pembelajaran. Penelitian ini dilakukan untuk meningkatkan kompetensi guru dan daya tarik siswa selama pelaksanaan School From Home (SFH) berdasarkan hasil belajar siswa.

\section{METODE PENELITIAN}

Pada penelitian ini, penulis menggunakan metode penelitian pengembangan atau Research \& Development $(R \& D)$. Research \& Development merupakan penelitian yang didefinisikan sebagai jenis penelitian yang memfokuskan diri pada tujuan mengembangkan, memperluas, dan menggali lebih jauh atas sebuah dasar teori dalam disipilin ilmu tertentu.

Penelitian ini dilakukan pada kelas VI SDN Krembangan Selatan III pada semester ganjil/genap tahun pelajaran 2020/2021 dengan subjek 30 siswa. Aplikasi yang digunakan 
dalam penelitian ini adalah aplikasi Canva. Objek penelitian adalah nilai peserta didik sebelum dan sesudah aplikasi canva diterapkan dalam pembelajaran dimana siswa mendengarkan dan memerhatikan penjelasan yang diberikan kemudain menulis beberapa pertanyaan terkait materi yang diberikan lalu menyimpulkan materi yang telah disampaikan melalui aplikasi Canva. Data yang diperoleh akan disajikan dalam bentuk diagram.

Jenis penelitian yang digunakan adalah penelitian kualitatif kuantitatif. Kualitatif diperoleh dari proses penyusunan media pembelajaran menggunakan aplikasi Canva serta mendeskripsikan hasil belajar siswa berdasarkan nilai akhir. Sedangkan data kuantitatif diperoleh dari penghitungan nilai siswa berupa penskoran hasil belajar siswa.

Pengumpulan data pada penelitian ini menggunakan beberapa instrumen yaitu:

1. Dokumentasi, data berupa dokumen-dokumen penunjang data penelitian serta foto-foto selama penelitian berlangsung,

2. Soal evaluasi siswa. yang diberikan setelah proses pembelajaran menggunakan aplikasi canva dilakukan.

\section{HASIL DAN PEMBAHASAN}

Perkembangan teknologi dan informasi saat ini menjadi salah satu hal yang signifikan terlebih di masa pandemic seperti ini. Salah satunya adalah perkembangan teknologi dan informasi dalam bentuk media untuk mempermudah proses belajar mengajar. Pemanfaatan media pembelajaran merupakan salah satu elemen yang berperan penting dalam keberhasilan proses pembelajaran terlebih saat pandemic seperti ini sedang berlangsung. Media pembelajaran adalah sesuatu yang digunakan untuk menyampaikan materi atau informasi dalam proses belajar mengajar.

Media pembelajaran merupakan alat yang digunakan sebagai penyalur informasi kepada penerimanya sehingga peerima dapat melakukan proses belajar mengajar secara efektif dan efisien yang akan menciptakan lingkungan belajar yang kondusif dan dapat lebih menarik minat siswa untuk belajar (Munadi, 2008:7). Media pembelajaran berperan penting dalam proses penyampaian materi agar materi yang di sampaikan lebih mudah diterima oleh siswa terlebih saat kegiatan belajar mengajar dilakukan secara daring seperti saat ini. Oleh sebab itu dibutuhkan berbagai aplikasi pembelajaran untuk menyampaikan materi ajar dalam pembelajaran jarak jauh, salah satunya adalah aplikasi Canva. Pendidikan bersifat interaktif, menyeluruh, dan mudah digunakan secara virtual. Kelebihan yang dimiliki aplikasi ini adalah mudahnya aplikasi ini di akses melalui ponsel. Menurut Faiza (2019), aplikasi Canva memiliki desain yang menarik, sehingga mampu meningkatkan kreativitias guru dan siswa dalam mendesain media pembelajaran karena fitur-fitur di dalam aplikasi ini pun sangat mudah digunakan, menghemat waktu dalam mendesain media pembelajaran. Dengan penggunaan aplikasi ini, diharapkan siswa dapat meningkatkanhasil belajar mereka secara efektif dan efisien.

Sebelum melakukan tindakan, penliti melakukan obesrvasi pada siswa kelas VI SDN Krembangan Selatan III. Kegiatan yang dilakukan yaitu mengamati nilai hasil belajar siswa pada pembelajaran yang sebelumnya sudah dilakukan. Berdasarkan hasil observasi sebelum dilakukan tindakan, nilai siswa kelas VI berada dibawah KKM yang sudah ditentukan yaitu 75 . Dari hasil ini, peneliti menemukan bahwa keaadan kelas daring saat proses belajar mengajar berlangsung tidak efektif dan efisien serta kurangnya minat belajar siswa kelas VI saat kelas daring sedang berlangsung, Karena itu, peneliti menggunakan aplikasi Canva sebagai media pembelajaran agar siswa lebih aktif dan interaktif sehingga siswa dapat mengalami prestasi belajar menjadi lebih baik. Hasil belajar siswa sebelum dan setelah penggunaan aplikasi Canva.

Tabel 1. Data Nilai siswa sebelum menggunakan aplikasi canva

\begin{tabular}{|c|l|c|c|c|}
\hline NO & \multicolumn{1}{|c|}{ NAMA SISWA } & KKM & NILAI & KET \\
\hline 1 & $\begin{array}{l}\text { ACHMAD ALIEF } \\
\text { ZAINI }\end{array}$ & 75 & 60 & $\begin{array}{c}\text { Tidak } \\
\text { Tuntas }\end{array}$ \\
\hline
\end{tabular}


Vol 1. No. 4, Oktober 2021 P-ISSN : 2774-8014, e-ISSN : 2774-7034

\begin{tabular}{|c|c|c|c|c|}
\hline 2 & $\begin{array}{l}\text { AMIRA FAUHA } \\
\text { SALSABILA }\end{array}$ & 75 & 68 & $\begin{array}{l}\text { Tidak } \\
\text { Tuntas }\end{array}$ \\
\hline 3 & ARGA DACOSTA & 75 & 65 & $\begin{array}{l}\text { Tidak } \\
\text { Tuntas }\end{array}$ \\
\hline 4 & BADRUD TAMAM & 75 & 80 & Tuntas \\
\hline 5 & CAMELIA AULIA & 75 & 55 & $\begin{array}{l}\text { Tidak } \\
\text { Tuntas }\end{array}$ \\
\hline 6 & $\begin{array}{l}\text { DAVID ACHMAD } \\
\text { SATRIAWAN }\end{array}$ & 75 & 80 & Tuntas \\
\hline 7 & FIKRI KAYSAN ALI & 75 & 50 & $\begin{array}{l}\text { Tidak } \\
\text { Tuntas }\end{array}$ \\
\hline 8 & IFDHOLUL AROBI & 75 & 65 & $\begin{array}{l}\text { Tidak } \\
\text { Tuntas }\end{array}$ \\
\hline 9 & KOMARUDDIN & 75 & 80 & Tuntas \\
\hline 10 & LABIB IHAB AL AZIZ & 75 & 65 & $\begin{array}{l}\text { Tidak } \\
\text { Tuntas }\end{array}$ \\
\hline 11 & $\begin{array}{l}\text { MAULIDYA } \\
\text { KHOIRUDIN }\end{array}$ & 75 & 68 & $\begin{array}{l}\text { Tidak } \\
\text { Tuntas }\end{array}$ \\
\hline 12 & $\begin{array}{l}\text { MOCH RISKI NANA } \\
\text { KHAHFI }\end{array}$ & 75 & 80 & Tuntas \\
\hline 13 & $\begin{array}{l}\text { MOCHAMMAD } \\
\text { QOMARUL ANAM }\end{array}$ & 75 & 76 & Tuntas \\
\hline 14 & $\begin{array}{l}\text { MOCHAMMAD } \\
\text { RAMZI }\end{array}$ & 75 & 65 & $\begin{array}{l}\text { Tidak } \\
\text { Tuntas }\end{array}$ \\
\hline 15 & $\begin{array}{l}\text { MOH HAMDANI } \\
\text { SAKUR }\end{array}$ & 75 & 56 & $\begin{array}{l}\text { Tidak } \\
\text { Tuntas }\end{array}$ \\
\hline 16 & $\begin{array}{l}\text { MOHAMMAD } \\
\text { FASHIHUL LISAN }\end{array}$ & 75 & 68 & $\begin{array}{l}\text { Tidak } \\
\text { Tuntas }\end{array}$ \\
\hline 17 & $\begin{array}{l}\text { MUHAMMAD IHWAN } \\
\text { SABANI }\end{array}$ & 75 & 82 & Tuntas \\
\hline 18 & $\begin{array}{l}\text { OKTA SYAWAL } \\
\text { NURHIJAZ AZHAR }\end{array}$ & 75 & 60 & $\begin{array}{l}\text { Tidak } \\
\text { Tuntas }\end{array}$ \\
\hline 19 & RAGIL AMMAR & 75 & 50 & $\begin{array}{l}\text { Tidak } \\
\text { Tuntas }\end{array}$ \\
\hline 20 & $\begin{array}{l}\text { RIFDAH AZALIA } \\
\text { ADRISTI }\end{array}$ & 75 & 84 & Tuntas \\
\hline 21 & RIRIS ATUL MUNAH & 75 & 65 & $\begin{array}{l}\text { Tidak } \\
\text { Tuntas }\end{array}$ \\
\hline 22 & RISKIA WANDIRA & 75 & 50 & $\begin{array}{l}\text { Tidak } \\
\text { Tuntas }\end{array}$ \\
\hline 23 & SAIFULLOH YUSUF & 75 & 60 & $\begin{array}{l}\text { Tidak } \\
\text { Tuntas }\end{array}$ \\
\hline 24 & $\begin{array}{l}\text { SALSA BELLA } \\
\text { ROHMAH }\end{array}$ & 75 & 84 & Tuntas \\
\hline 25 & $\begin{array}{l}\text { SASKIA NIHAL NUR } \\
\text { ZAENAH }\end{array}$ & 75 & 50 & $\begin{array}{l}\text { Tidak } \\
\text { Tuntas }\end{array}$ \\
\hline 26 & SITI ROHANA & 75 & 60 & $\begin{array}{l}\text { Tidak } \\
\text { Tuntas }\end{array}$ \\
\hline 27 & $\begin{array}{l}\text { SITI SYARIFATUL } \\
\text { AMANDA }\end{array}$ & 75 & 65 & $\begin{array}{l}\text { Tidak } \\
\text { Tuntas }\end{array}$ \\
\hline 28 & SYAFAATI FIRDAUS & 75 & 86 & Tuntas \\
\hline
\end{tabular}


Vol 1. No. 4, Oktober 2021 P-ISSN : 2774-8014, e-ISSN : 2774-7034

\begin{tabular}{|c|l|c|c|c|}
29 & SYIFA AULIA IDRIS & 75 & 65 & $\begin{array}{c}\text { Tidak } \\
\text { Tuntas }\end{array}$ \\
\hline 30 & VILZA SYAFARANI & 75 & 80 & Tuntas \\
\hline & & & & \\
\hline & JUMLAH & & 2022 & \\
\hline & RATA-RATA & & 67,4 & \\
\hline & Ketuntasan & & $33 \%$ & \\
\hline
\end{tabular}

Tabel 2. Data Nilai Siswa Setelah menggunakan aplikasi canva

\begin{tabular}{|c|c|c|c|c|}
\hline NO & NAMA SISWA & KKM & NILAI & KET \\
\hline 1 & ACHMAD ALIEF ZAINI & 75 & 84 & Tuntas \\
\hline 2 & $\begin{array}{l}\text { AMIRA FAUHA } \\
\text { SALSABILA }\end{array}$ & 75 & 80 & Tuntas \\
\hline 3 & ARGA DACOSTA & 75 & 72 & $\begin{array}{l}\text { Tidak } \\
\text { Tuntas }\end{array}$ \\
\hline 4 & BADRUD TAMAM & 75 & 82 & Tuntas \\
\hline 5 & CAMELIA AULIA & 75 & 85 & Tuntas \\
\hline 6 & $\begin{array}{l}\text { DAVID ACHMAD } \\
\text { SATRIAWAN }\end{array}$ & 75 & 90 & Tuntas \\
\hline 7 & FIKRI KAYSAN ALI & 75 & 80 & Tuntas \\
\hline 8 & IFDHOLUL AROBI & 75 & 70 & $\begin{array}{l}\text { Tidak } \\
\text { Tuntas }\end{array}$ \\
\hline 9 & KOMARUDDIN & 75 & 82 & Tuntas \\
\hline 10 & LABIB IHAB AL AZIZ & 75 & 80 & Tuntas \\
\hline 11 & $\begin{array}{l}\text { MAULIDYA } \\
\text { KHOIRUDIN }\end{array}$ & 75 & 84 & Tuntas \\
\hline 12 & $\begin{array}{l}\text { MOCH RISKI NANA } \\
\text { KHAHFI }\end{array}$ & 75 & 86 & Tuntas \\
\hline 13 & $\begin{array}{l}\text { MOCHAMMAD } \\
\text { QOMARUL ANAM }\end{array}$ & 75 & 85 & Tuntas \\
\hline 14 & MOCHAMMAD RAMZI & 75 & 80 & Tuntas \\
\hline 15 & $\begin{array}{l}\text { MOH HAMDANI } \\
\text { SAKUR }\end{array}$ & 75 & 80 & Tuntas \\
\hline 16 & $\begin{array}{l}\text { MOHAMMAD } \\
\text { FASHIHUL LISAN }\end{array}$ & 75 & 90 & Tuntas \\
\hline 17 & $\begin{array}{l}\text { MUHAMMAD IHWAN } \\
\text { SABANI }\end{array}$ & 75 & 70 & $\begin{array}{l}\text { Tidak } \\
\text { Tuntas }\end{array}$ \\
\hline 18 & $\begin{array}{l}\text { OKTA SYAWAL } \\
\text { NURHIJAZ AZHAR }\end{array}$ & 75 & 85 & Tuntas \\
\hline 19 & RAGIL AMMAR & 75 & 80 & Tuntas \\
\hline 20 & $\begin{array}{l}\text { RIFDAH AZALIA } \\
\text { ADRISTI }\end{array}$ & 75 & 90 & Tuntas \\
\hline 21 & RIRIS ATUL MUNAH & 75 & 84 & Tuntas \\
\hline 22 & RISKIA WANDIRA & 75 & 80 & Tuntas \\
\hline 23 & SAIFULLOH YUSUF & 75 & 70 & $\begin{array}{l}\text { Tidak } \\
\text { Tuntas }\end{array}$ \\
\hline 24 & $\begin{array}{l}\text { SALSA BELLA } \\
\text { ROHMAH }\end{array}$ & 75 & 80 & Tuntas \\
\hline
\end{tabular}


Vol 1. No. 4, Oktober 2021 P-ISSN : 2774-8014, e-ISSN : 2774-7034

\begin{tabular}{|c|l|c|c|c|}
\hline 25 & SASKIA NIHAL NUR & & & \\
& ZAENAH & 75 & 82 & Tuntas \\
\hline 26 & SITI ROHANA & 75 & 85 & Tuntas \\
\hline 27 & $\begin{array}{l}\text { SITI SYARIFATUL } \\
\text { AMANDA }\end{array}$ & 75 & 80 & Tuntas \\
\hline 28 & SYAFAATI FIRDAUS & 75 & 84 & Tuntas \\
\hline 29 & SYIFA AULIA IDRIS & 75 & 88 & Tuntas \\
\hline 30 & VILZA SYAFARANI & 75 & 82 & Tuntas \\
\hline \multicolumn{2}{|c|}{ JUMLAH } & & 2450 & \\
\hline & RERATA & 82 & \\
\hline \multicolumn{2}{|c|}{ Ketuntasan } & $87 \%$ & \\
\hline
\end{tabular}

Pada tabel 2 di atas menjelaskan jumlah siswa yang lolos KKM sebelum penggunakan aplikasi Canva sebagai media pembelajaran., jumlah siswa yang nilainya lolos KKM hanya 10 orang, dengan rata-rata nilai 67,4. Pada tabel 2 data siswa setelah menggunakan aplikasi canva jumlah siswa yang nilainya lolos KKM 26 orang, dengan rata-rata nilai 82 dapat dilihat dari grafik di bawah ini. Pada grafik 1, menjelaskan prsentase siswa yang lolos KKM sebesar 33\% sebelum penggunaan aplikasi Canva dan kemudian naik menjadi $87 \%$ sesudah penggunaan aplikasi Canva. Untuk melihat peningkatan nilai rata-rata siswa dapat dilihat dalam grafik 2.

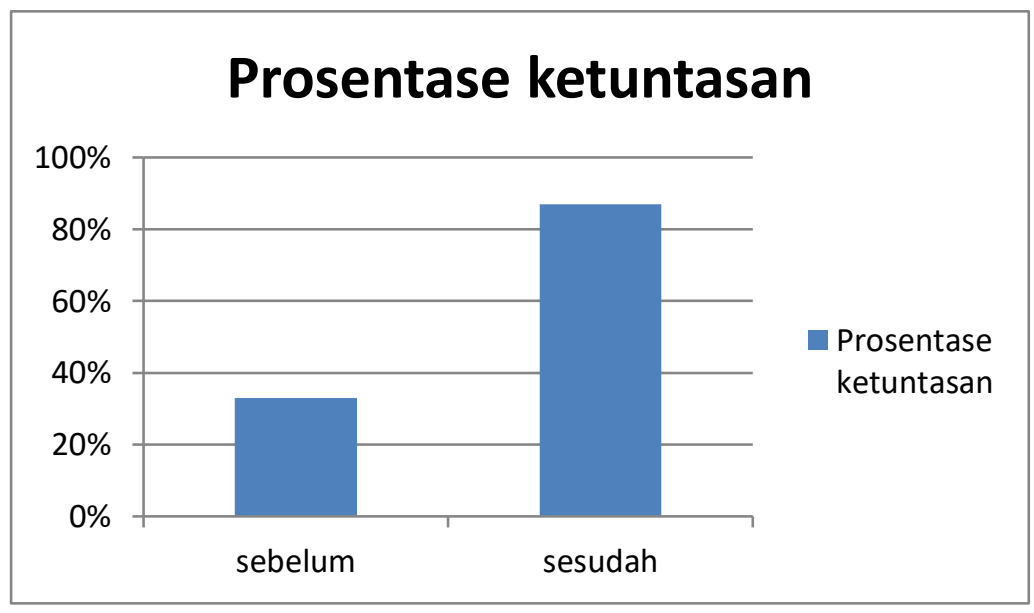

Gambar 1. Hasil Ketuntasan Peserta Didik

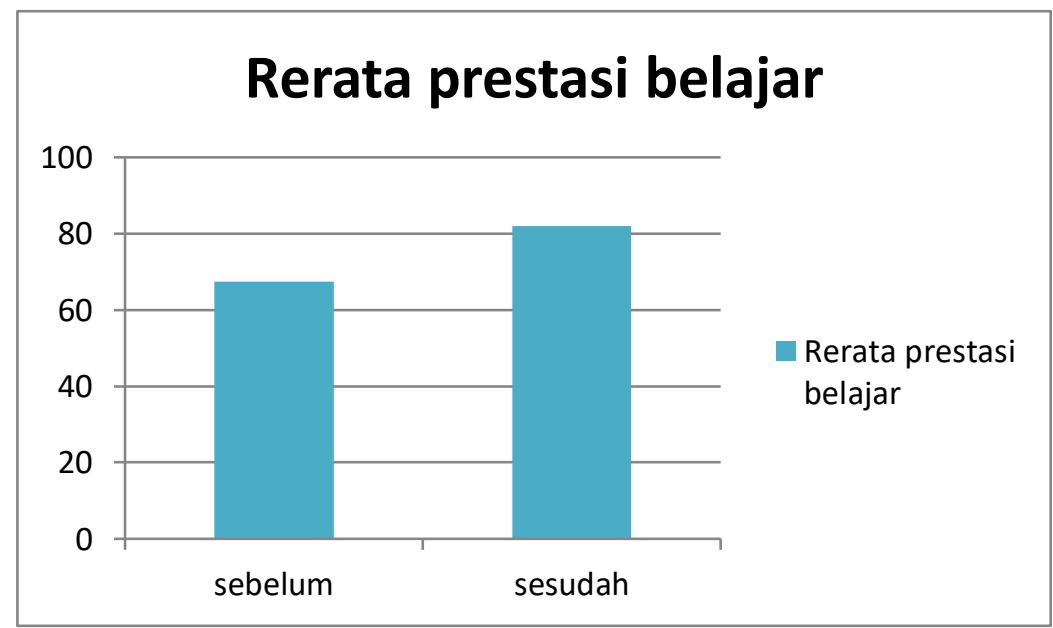

Gambar 2. Grafik Peningkatan Nilai Rata-rata Siswa 
Grafik diatasa menunjukkan bahwa terjadi peningkatan nilai rata-rata siswa sesudah menggunakan aplikasi Canva sebagai media pembelajaran. Sebelum menggunakan aplikasi canva, nilai rata-rata siswa hanya sebesar 67,4 setelah penggunaan aplikasi Canva nilai ratarata siswa meningkat menjadi 82. Hal ini sejalan dengan penelitian Pelangi [2020] yang menyatakan bahwa dengan desain yang beragam dan menarik, membuat proses pembelajaran menjadi tidak membosankan. Dengan menggunakan aplikasi Canva, guru dapat mengajarkan ilmu pengetahuan, kreativitas, serta keterampilan yang akan didapatkan untuk peserta didik, sehingga media ini juga dapat dimanfaatkan dalam berbagai ranah kehidupan. Siswa dapat memahami materi dengan baik jika media pembelajaran dibuat dengan menarik dan tepat (Sutarno \& Mukhidin, 2013). Jika dikaitkan dengan teori kerucut pengalaman (Cone of Experience), bahwa 50 persen pengetahuan atau pengalaman belajar diperoleh dari indra penglihatan dan pendengaran. Multimedia yang menggabungkan indra manusia memudahkan pencapaian kompetensi dan pemahaman siswa (Said, 2016).

\section{KESIMPULAN}

Dari uraian diatas dapat disimpulkan bahwa penggunaan canva untuk meningkatkan kreativitas dan prestasi belajar siswa dalam pembelajaran daring di masa pandemic COVID-19 sangat efektif digunakan karea fitur-fitur yang tersedia di dalamnya beragam dan dapat digunakan dengan mudah baik oleh guru atau siswa. Hal ini dibuktikan dengan meningkatnya nilai dan prestasi belajar siswa setelah penggunaan aplikasi canva sebagai media pembelajaran. Diharapkan aplikasi ini dapat terus menjadi media pembelajaran yang efektif dan efisen untuk kemudian hari

\section{DAFTAR PUSTAKA}

Budiman, H. (2017). Peran Teknologi Informasi dan Komunikasi dalam Pendidikan. AlTadzkiyyah: Jurnal Pendidikan Islam 8(1), 31-43.

Canva. (s.f.). Canva Untuk Pendidikan. Retrieved from www.canva.com: https://www.vanva.com/id_id/pendidikan/

Hapsari, G. P. (2021). Pengembangan Media Video Animasi Berbasis Aplikasi Canva untuk Meningkatkan Motivasi dan Prestasi Belajar Siswa. . Jurnal Basicedu, 5(4)., 23842394.

Miftah, M. (2014). Pemanfaatan Media Pembelejaran untuk Peningkatan Kualitas Belajar Siswa. Kwangsan.

Pelangi, G. (2020). Pemanfaatan Aplikasi Canva Sebagai Media Pmebelajaran Bahas dan Sasra Indonesia Jenjang SMA/MA. Jurnal Sasindo UNPAM, 79-96.

Rahmatullah, R. I. (2020). Media Pembelajaran Audio Visual Berbasis Aplikasi Canva. Jurnal Pendidikan Ekonimi Undiksha, 12(2), 317-327.

Said, A. A. (2016). "Desain Multimedia Pembelajaran". Seminar Nasional "Revitalisasi

Pendidikan Seni Dan Desain Sebagai Basis Pengembangan SDM," 1, 239

Sutarno, E., \& Mukhidin. (2013). "Pengembangan Model Pembelajaran Berbasis Multimedia Interaktif Pengukuran Untuk Meningkatkan Hasil Dan Kemandirian Belajar Siswa Smp Di Kota Bandung". sJurnal Pendidikan Teknologi Dan Kejuruan, 21(3), 203218.

Tanjung, R. E. (2019). Canva Sebagai Media Pembelajaran Pada Mata Pelajaran Dasar Listrik Dan Elektronika. VoteTEKNIKA: Jurnal Vocational Teknik Elektronika dan Informatika, 7(2)., 79-85. 